\title{
Indígenas, catequesis y civilización en la Provincia de Minas (Brasil, siglo XIX)
}

Aceptación: Diciembre - 2007

Aprobación: Marzo - 2008

Izabel Missagia de Mattos*

\section{RESUMEN}

El presente artículo trata sobre un período en el cual una numerosa población indígena "desapareció" tanto en la Provincia de Minas Gerais, foco de este estudio, así como en todo Brasil. El análisis de la historia de los grupos indígenas corresponde al establecimiento de un modelo "civilizador" de administración indígena y otorga visibilidad a los mecanismos a través de los cuales se planificó y llevó a cabo el proceso de "desaparición". Por otro lado, sin embargo, dicho análisis revela los fracasos observables en las situaciones y prácticas cotidianas de los aldeamientos.

Se analizan algunos episodios, como la revuelta de los indios considerados "civilizados" en la misión de Itambacuri en el año 1893 (después de 20 años de catequesis misionera), como metáfora de las relaciones de contradicción existentes entre las fuerzas actuantes por la integración nacionalizadora y las que detonaron movimientos de división, que luchaban por la recuperación de la autonomía local.

La posibilidad de articulación entre la perspectiva etnológica e histórica orientó el abordaje teórico, de modo que la acción de los actores indígenas fue cotejada en relación a las concepciones nativas, aunque la actualización de estas concepciones asumiera diversas formas en las diferentes situaciones analizadas De esta forma, la investigación del fenómeno empírico de la dinámica de las identidades indígenas en la situación colonial puede revelar tanto sus directrices históricas, fornecidas principalmente por las prácticas indigenistas coetáneas, como su contracara nativa, la de los procesos etnopolíticos.

PALABRAS CLAVE: misiones Minas Gerais, colonización Minas Gerais, Botocudos, indígenas Minas Gerais.

\section{ABSTRACT}

This comunication focuses on a period of time during which a great indigenous population "disappeared" in the province of Minas Gerais, as well as in the whole country of Brazil. The examination of the indigenous people's history corresponds to the introduction of a "civilizator" model of administration of indigenous population and supplies visibility to the mechanisms through which the "disappearance" process was planned and carried out, revealing, in other hand, its failures, (which are) noticeable in daily situations and practices in the settlements.

Episodes such as the revolt of the indigenous population thoght to be "civilized" in the Itambacuri mission in the year of 1893, after 20 years of missionary catechesis, were analysed as a metaphor of the existing relations of contradiction between the forces acting for the nationalizing integration and those acting for the outbreak of divisional movements, fighting for recuperation of local autonomy.

The possibility of articulation between the ethnological and historical perspectives guided the theoretical approach; the action of the indigenous actors was compared to the native conceptions, even though the updating of these has assumed many different shapes in the different examined situations. Then, the investigation of the empirical phenomen of the indigenous identities dynamics in the examined colonial situation was able to reveal its historical criteria, supplied mainly by the coethaneous indigenist practices, as well as its native counterpart, the one of the ethnopolitical processes.

KEY WORDS: missiones Minas Gerais, colonización Minas Gerais, Botocudos, indígenas Minas Gerais.

\footnotetext{
* Doctora en Ciencias Sociales (especialista en Sociedades Indígenas, por la Universidad Estadual de Campinas [Unicamp]) y
} profesora de la Universidad Federal de Goiás, Brasil, belmissagia@gmail.com 


\section{Introducción}

En Brasil, en el siglo XIX, fue implantado y concebido un modelo "civilizador" de administración indígena, al mismo tiempo en que una numerosa población indígena "desaparecía". Si bien los mecanismos de este proceso de "desaparición" pueden ser develados por el propio examen de las políticas públicas, adoptadas oficialmente para tratar el problema que representaba la existencia de poblaciones indígenas en el país, también pueden ser observadas las prácticas cotidianas de los indígenas administrados, las cuales revelan el fracaso de la ejecución de tales proyectos civilizatorios. En efecto, el protagonismo de los indígenas en las situaciones de aldeamiento* produjo conflictos habituales, los que forzaron negociaciones políticas entre los intereses indígenas por autonomía y los proyectos de construcción de una nación étnicamente homogénea.

La trayectoria investigada de los pueblos de las Provincias de Minas Gerais -lugar donde ocurrieron fenómenos de "rebeldías" indígenas en los aldeamientos de las misiones - apunta hacia la necesidad de un abordaje situacional de aquellos movimientos, comprendidos al interior de complejos sistemas de relaciones interétnicas.

El movimiento de recomposición de identidades y de formas societarias indígenas a analizar, investigado aquí en el caso de los Botocudos, fue relacionado a los aspectos institucionales e ideológicos de la política adoptada para contener el "problema indígena" en el período imperial (1822-1889). Sin embargo, el discurso "civilizador" del período en cuestión extrapolaba el problema propiamente indígena debido, en parte, a la relevancia otorgada en ese entonces a la esclavitud -abolida, finalmente, en 1888- y al "problema racial" representado por la población afrodescendiente. Ambos elementos fueron claves para la planificación económica del país. De este modo, tanto el incentivo a la inmigración europea y al mestizaje, así como la redefinición del destino de los territorios "libres" (léase indígenas), se constituyeron como medidas que buscaban solucionar la carencia de mano de obra para el trabajo agrícola y para la naciente industria después del fin de la esclavitud.

Algunos factores endógenos habían influenciado en la configuración de las frecuentes movilizaciones colectivas de los Botocudos radicados en aldeas por los misioneros capuchinos de la Provincia de Minas (1873-1893), examinados en un estudio anterior, habiendo sido investigados, sobre todo, en lo que respecta a las lógicas de conocimiento y de organización sociopolítica nativas. (MISSAGIA DE MATTOS, 2004).

En los relatos de los viajeros y políticos ilustrados que describieron las selvas y los salvajes en las cuencas de los ríos Mucuri, Jequitinhonha y Dulce, situadas en la Provincia de Minas Gerais, en la segunda mitad del siglo XIX, aparecen, por ejemplo, dos tipos de "problema indígena" relacionados a los Botocudos: la degradación física y moral de los Naknenuk -considerados "mansos"- y la ferocidad y la antropofagia atribuidas a los Giporok.

Ambos problemas se articulan con la clasificación operacionalizada por los colonizadores del río Mucuri para describir los dos "tipos ideales" de Botocudos. La investigación del proceso exógeno de identificación étnica revela la atribución de valores étnicos a partir de la constatación de una mayor o menor apertura de aquellos grupos indígenas para el establecimiento de alianzas y "mezclas" con los demás actores.

A pesar de compartir una misma lengua, articulada a un único sistema sociocosmológico, los pueblos denominados Naknenuk y Giporok fueron habitualmente considerados,

\footnotetext{
N. del T. Aldeamento (en portugués) es un concepto utilizado corrientemente en el contexto de la etnología indígena brasileña para designar los procesos a partir de los cuales son intervenidos los territorios "tradicionales" de diversos grupos indígenas por parte de la esfera política, social o religiosa hegemónica, prescribiendo un territorio determinado a un conjunto de individuos y grupos sociales. Los aldeamientos guaraníes planificados por los jesuitas en el período colonial (las misiones jesuíticas) constituyen el ejemplo clásico de este fenómeno de territorialización. En la lengua española algunos conceptos similares, pero no equivalentes, han sido usados para designar este fenómeno, como "reducción" (creación de reducciones o reservas) o "radicación". Sin embargo, he decidido mantener el concepto original, traducido al español como "aldeamiento", para entender mejor las especificidades aquí tratadas.
} 
en las fuentes documentales, como "confederaciones", distinguibles por determinadas características sociopolíticas. Las dos "confederaciones", subdivididas en "bandos" -segmentos residenciales oriundos de disputas faccionales internas- conocidos externamente con el nombre de uno de sus líderes y compuestos por familias extensas, habían sido conocidas, según la lógica colonizadora -o "civilizadora"-, por su disponibilidad para el "comercio", lo que encontró resonancia en el proceso etnopolítico de división faccional, tradicional entre los Botocudos. De esta forma, la clasificación identitaria observada en las fuentes para ambos "tipos" de Botocudos, aun siendo pautada por tales criterios etnopolíticos nativos, sería operacionalizada en la situación histórica, de acuerdo con la naturaleza del contacto establecido con los colonos forasteros.

Aunque la utilización del instrumental etnológico se mostró adecuado para la aprehensión de las estructuras indígenas en el marco del estudio de la organización política de los Botocudos, y aun habiendo iluminado aspectos inherentes a la etnopolítica, la aprehensión de las formas indígenas en movimiento se reveló poco productiva sin la debida adecuación y ajuste a la situación histórica de los nativos. En este sentido, las situaciones examinadas etnográficamente demuestran cómo los movimientos indígenas constituyeron, en gran medida, expresiones de "conciencia histórica", concebida por estos ante el asedio de segmentos diversos de la sociedad nacional sobre su territorio.

En efecto, la articulación de una "conciencia histórica" en el pensamiento indígena fue identificada en la investigación sobre la historia de los Botocudos de la Provincia de Minas, a través del lenguaje del chamanismo, íntimamente relacionado con las formas y estrategias políticas tradicionales de los pueblos nativos. El acompañamiento de los episodios relacionados a las situaciones de "rebeldía" de las poblaciones aldeadas revela cómo el idioma del chamanismo, compartido por los diversos subgrupos Botocudos, suministró elementos para la interpretación de la experiencia histórica de las situaciones de poblamiento y los orientó, al mismo tiempo, en sus estrategias de supervivencia colectiva.
La investigación pretendió, asimismo, acompañar etnográficamente los procesos de sustentación de formas y estrategias indígenas por medio de la identificación de determinadas regularidades que modelaron las relaciones entre los diversos actores colectivos insertos en una red de relaciones intersocietarias instauradas por el indigenismo, en especial las ocurridas al interior de los aldeamientos oficiales de la Provincia de Minas.

El abordaje utilizado en la interpretación de las situaciones investigadas surge del presupuesto, inmerso en el campo de la antropología histórica, que establece que los contextos históricos suministran elementos importantes para la configuración de redes de significados, que componen el análisis de los fenómenos observados. La ampliación de las escalas espaciales y temporales en la interpretación etnográfica pasa a ser concebida, en ese tipo de abordaje, como una contribución efectiva para la iluminación de los fenómenos analizados, sean ellos contemporáneos 0 , como en el caso aquí discutido, encaminados al pasado.

La siguiente exposición se refiere a las reflexiones sobre movimientos indígenas en el siglo XIX y de sus relaciones con el Estado brasileño.

\section{Los indígenas y la nación en el siglo XIX}

Los principales instrumentos de la política imperial relacionados al "gobierno" de los indígenas en Brasil, fueron los Decretos 285 y 426 del 24 de junio de 1843 y de 24 de julio de 1845, respectivamente.

Mientras el primer Decreto autorizaba al gobierno a contratar específicamente misioneros capuchinos italianos y distribuirlos entre las provincias en las misiones indígenas, confiriéndoles un amplio control sobre la política indigenista en el II Reinado, el segundo, de 1845, también conocido como Regulamento das Missões (Reglamento de las Misiones), delineaba el sistema administrativo de la política indigenista, centrado en la figura de los directores generales de los indios. Esos directores, que eran nombrados directamente por el Emperador para actuar en la estructura administrativa provincial, ejercían la función tutelar 
del Estado en la mediación entre los indígenas y la sociedad nacional, conjuntamente con los directores parciales y los directores en las aldeas. Tal sistema tutelar, extinto con la proclamación de la república (1889), solo sería substituido con la creación del Serviço de Proteção aos Índios e Localização de Trabalhadores Nacionais (Servicio de Protección a los Indios y Localización de Trabajadores Nacionales - SPILTN) en 1910. Durante este período de vacío en la legislación indigenista y en la acción del poder central sobre las poblaciones indígenas, la administración de los grupos indígenas quedó bajo el cometido ( $\mathrm{y}$ a los infortunios) de las esferas del poder regional y local. En este período se hace notar en diversas regiones del país la intensificación de la presión territorial sobre los grupos indígenas, especialmente en los estados del nordeste, sudeste y sur.

G. Seyferth (1995) mostró como, a partir de mediados del siglo XIX, "el mestizaje y sus efectos [constituyeron] como el tema central en la interpretación orgánica de la historia de Brasil y de las especulaciones acerca del futuro de la nación". Para la autora, la ideología subyacente al discurso ilustrado y "científico" sobre la "formación (étnica) brasilera" sería constituida a partir de una paradoja que se puede expresar en la coexistencia necesaria de los temas de la abolición de la esclavitud y de la inmigración. Están datadas, de hecho, a partir de 1850, tanto el fin del tráfico negrero como la formulación de una política inmigratoria consistente bajo la Ley de Tierras.

Las contradicciones entre las concepciones ilustradas del discurso indigenista y su práctica en las regiones de las provincias se encuentran presentes durante la segunda mitad del siglo XIX, en el momento en que la idea de la difusión de una "raza mestiza" era vista como la única salida para la "resolución" del problema indígena, es decir, de la plena inserción de los grupos indígenas a la vida "social", -entendida como "civilizada", a diferencia de su vida "salvaje".

El presupuesto de la inferioridad racial del indígena y del mestizo fue expresado también en la distribución diferencial de las tierras. Los inmigrantes extranjeros, considerados más aptos para la colonización del país, ocuparon las tierras "expropiadas" de los ocupantes tradicionales (terras devolutas*), y los "indios civilizados" permanecieron al margen del proceso de colonización (SEYFERTH 1995a: 60).

A lo largo del período de crisis sufrido por el régimen monárquico brasilero, la creencia en la regeneración de la humanidad por la ciencia, que caracterizó la filosofía de Augusto Comte, se generalizó en Brasil. En este mismo período transitorio para la república, se habían contabilizado diversas situaciones de inestabilidad política y la existencia de revueltas populares en todo el país. El problema de la tutela de los pueblos indígenas fue colocada en el centro de los debates que habían opuesto a la Iglesia y al Estado.

Sin embargo, el cambio de régimen no contribuyó para transformar la inmensa distancia creada entre los "indígenas" y los "civilizados". Una vez proclamada la república, el asunto de la catequesis se transformó en una atribución de los gobiernos de los estados, lo que aumentaba, en la práctica, las dificultades con respecto a la captación de recursos específicos, políticamente negociables, problema ya presente y vislumbrado en los últimos años del período imperial por el Directorio de los Indios de la Provincia, que tuvo su último representante oficial hasta el año 1894. Solo en 1911, tras el término de la repartición, tuvieron inicio las actividades del Servicio de Protección a los Indios y Localización de Trabajadores Nacionales (SPILTN), que inmediatamente instaló "puestos de atracción" para los Botocudos que vivían en las selvas de São Mateus y del río Dulce.

\section{La extinción del siglo de las luces y el pro- blema de la Catequesis}

En las últimas décadas del siglo XIX, el discurso sobre la "catequesis" expresaba más claramente sus fundamentos. La preocupación humanitaria sería poco a poco substituida por

N. del T. En el lenguaje jurídico brasilero es usual la expresión "terras devolutas" para definir el conjunto de tierras consideradas "públicas" (generalmente expropiadas a poblaciones nativas), las cuales no poseen ningún tipo de utilización pública específica y que no se encuentran, por cualquier título, integradas al dominio privado. 
un discurso legalista, que abarcaba, inclusive, los derechos de los “indígenas" y, evidentemente, definía también sus deberes. Aquí, otra vez, es posible percibir un punto de convergencia entre los significados de la revisión legalista del problema del esclavo negro y el de la catequesis indígena. El director general Manuel Ferreira, en su informe al presidente de la Provincia, en marzo de 1887, evaluaba que si los esfuerzos gubernamentales para la catequesis hubieren sido siempre más racionales -como por ejemplo en el caso de las misiones jesuitas- “(...) esos groseros habitantes de la mata virgen ya estarían convertidos en hombres de trabajo, y [sus] musculosos brazos retemplados en las crudezas del tiempo, sin duda prestarían hoy mucho al país, en la conversión del brazo esclavo por el brazo libre". Y continuaba, pregonando las ventajas posibles de la continuidad de inversiones gubernamentales en el sector de la catequesis: "Aun dándose la hipótesis de que no hubiese ventaja en la conversión de esos leones de los bosques en hombres del trabajo y de las artes, ¿no sería también de gran utilidad salvaguardar al viajante y al labrador de las correrías de esos hombres sin imputabilidad"1.

La existencia de "salvajes" indiferentes al "progreso" figuraría de una forma cada vez más anacrónica en una nación concebida en estado de "perfeccionamiento", pasando a ser concebida como "problema", tal como el propio servicio público creado para administrarlo. A pesar de ser ineludible en la pauta de las políticas sociales, el asunto de la "catequesis", en los últimos años del Imperio, caminó hacia un nítido proceso de una paulatina (y optimista) extinción. El "problema de la catequesis" solo podría ser solucionado con el desarrollo económico, se pensaba entonces. $Y$ fue lo que de hecho parece haber ocurrido con la transición de régimen, sobre todo si indagamos que el asunto de la "civilización de los indios", en el inicio de la república, desapareció de los espacios de los informes oficiales destinados a la colonización de las tierras, lo que no ocurrió con los proyectos como el de construcción de una gama de redes ferroviarias, que debería recortar todo el país bajo el régimen republicano.

\section{La revuelta del los indígenas en la misión de Itambacuri, Minas Gerais}

En 1893 ocurrió una revuelta indígena de amplias proporciones en el poblado misionero de Itambacuri -establecido en 1872 en la Provincia de Minas Gerais-, región en la que el ejercicio del poder a través de la violencia física marcó todo el período de colonización. Los significados de la revuelta de los indígenas de Itambacuri, por el hecho de que ocurrió en medio a los procesos de transición hacia la república, son capaces de expresar los conflictos experimentados por los diversos actores, ya sea al interior del poblado, o en sus relaciones con las fuerzas políticas externas.

Uno de los primeros registros sobre el levantamiento data del 10 de junio de 1893 . Se trata de correspondencia enviada por el director de la $3^{\mathrm{a}}$. Circunscripción de los Indios de la Provincia y juez de paz en ejercicio, al director general de los Indios, en la cual se mostraba visiblemente impactado por las "escenas verdaderamente horrorosas" testimoniadas en el poblado de Itambacuri, que "hasta hace bien poco tiempo fue el punto más próspero del norte de Minas": los indígenas, sublevándose contra los misioneros, cometieron asesinatos utilizando las armas de fuego suministradas por los sacerdotes, hirieron de flecha a personas que iban a trabajar en las labranzas, quemaron "todas las casas localizadas en las zonas de rozas y con estas todos los depósitos de manutención pertenecientes a los nacionales allí establecidos", mataron todos los animales domésticos que encontraron y destruyeron los puentes.

En represalia, algunas expediciones fueron planificadas entre la población con la finalidad de "cazar" a los indígenas que huyeron hacia la selva. En algunas de estas expediciones, según relató el ingeniero Pedro Versiani, responsable en la apuración de denuncias relativas a la administración de la catequesis encaminadas a la Secretaría de Agricultura, Comercio y Obras Públicas del Estado, tras la revuelta, tomó partido "la policía provincial para garantizar la vida y la propiedad de los individuos amenazados".

1 Relatório do diretor geral dos índios, Manoel de Paula Ferreira, ao presidente da Província com cópia para o ministro da Agricultura. 5 de março de 1887. SG 22, p. 180. 
El objetivo de la revuelta, según los administradores, era la apropiación del Establecimiento por parte de los indios, que, muy pretenciosamente, tenían como objetivo vivir del trabajo ajeno, como si fuesen señores de las tierras y esclavos.

El documento más completo y detallado sobre este episodio es un informe redactado el 22 de agosto de 1893 por los misioneros, dirigido al director general de los indios del Estado de Minas Gerais, brigadier Antônio Alves Pereira da Silva, quien, en principio, acusaba como uno de los principales mentores del movimiento al que "quiso ser considerado como jefe de los indios del Potão, donde tiene padrinos de bautismo", considerándose como padrinos los miembros de la familia Otoni.

La eficacia de la movilización indígena se debió sobre todo a la intensificación de prácticas rituales observadas en el movimiento que antecedió algunos meses la eclosión de la revuelta, cuya dinámica se caracterizó por la insatisfacción de los indios aldeados con la situación de enfermedad y privación que vivían, siendo la causa de sus maleficios atribuida a la existencia de los misioneros. "Reuniones nocturnas" -como las observadas entre los indios "civilizados" durante la preparación de la revuelta- acontecían entre los pueblos Botocudos cuando, basados en una lógica chamánica, se articulaban alrededor de estrategias políticas con la finalidad de vengar la muerte de sus parientes. Estas "danzas nocturnas" proporcionaban a los indígenas un sentido en relación a las pérdidas sufridas a través de las acusaciones de hechicería enemiga, preparándolos ritualmente para los ataques, efectuados bajo la forma de una "revuelta", como fue traducida por los términos del indigenismo misioneros de aquel violento fin de siglo.

De acuerdo con el relato de los frailes Serafín de Gorizia y Ángelo de Sassoferrato, los indígenas se prepararon, entonces, ritualmente, para la guerra, cuando se pintaban con la tinta roja del urucum.

Ao anoitecer do dia 24 de maio de 1893, os índios munidos de seus arcos e frechas, tingidos de urucu ... [prepararam-se para] matar a nós ambos e a afugentar os civilizados e apossarem-se ... de tudo: mantimentos, criação, mercadorias, etc... (apud Palazzolo, 1954 :253-252)*

Mediante la realización de tales "danzas", los misioneros tomaron sus "enérgicas providencias", las cuales, sin embargo, no tuvieron el efecto deseado. El director general de los indios, por su lado, esclarecía el tenor de las "enérgicas providencias" tomadas por los misioneros al presentir el peligro de la insurrección: era un intento de "corregir con cárcel a los más exaltados, con la finalidad de prevenir tan horrenda hecatombe".

En el informe de los misioneros sobre la revuelta solo los "indios civilizados" habían sido apuntados como participantes de la rebelión. Sin embargo, el director general de los indios advirtió que también los "nacionales que habían sido expulsados del poblado, ya sea por su pésimo comportamiento, o por participar de las reuniones nocturnas y sediciosas, continuaron agitando los ánimos de los indios, incentivándolos y seduciéndolos al punto de transformarse en peligro inminente e inevitable".

Lo más significativo en el movimiento que antecede a la revuelta es la forma como este permitió reunir e incorporar a los grupos indígenas "que vivían en el margen del río Itambacuri, en un número abundante, de casi 1.000 personas, en una distancia de 30 kilómetros", quienes fueron localizados, en trincheras, en las proximidades de la sede de la misión.

Solo los Pojichá, bastante diezmados por el sarampión que había brotado en aquel año, se recusaron a participar del movimiento. "Los líderes de los indígenas insurrectos", tras herir con flechas a los misioneros, y creyéndolos muertos, emprendieron un viaje para su aldea, invitando a los Pojichá a "tomar el aldeamiento, pues allí encontrarían gran cantidad de caseríos para vestuario, bebidas, he-

\footnotetext{
“Al anochecer del día 24 de mayo de 1893, los indios armados con sus arcos y flechas, teñidos de urucu ... [se alistaron para] matarnos a nosotros dos y para ahuyentar a los civilizados $y$, de ese modo, adueñarse ... de todo: provisiones, creación, mercancías, etc.".
} 
rramientas y muchos géneros del país, pertenecientes a los nacionales". Los Pojichá, que, según el director general de los indios, "siempre fueron bien tratados por los misioneros, quienes los agasajaban con ropas, herramientas, fusiles y municiones, cuando venían a visitar a los hijos en el poblado", rechazaron la invitación, refugiándose en la selva².

La estrategia de los indios era bastante sofisticada: una vez que los religiosos eran muertos, los "700 a 800" indígenas que estaban atrincherados en un campamento “inmediatamente al sur", a 5 kilómetros del Establecimiento, empezarían el ataque con el objetivo de "apoderarse" del mismo y retirar a las niñas indígenas del internado (habían 23 infantes indígenas internas, 12 de ellas Pojichá, "a quienes el sarampión había dado una oportunidad, ya que muchas vidas fueron segadas en el comienzo del año corriente [1893], sobre todo entre los propios Pogichás"). Otros indios, "de confianza" (de los misioneros o de los "revoltosos"?), permanecieron como "espías". De hecho, los indios atrincherados, después de flechar a los misioneros, empezaron a "avanzar y arremeter [sobre] las casas de labradores pobres..., destruyendo y arrasando todo lo que encontraron". Delante de este escenario, los nacionales habitantes del poblado huyeron en dirección al bosque.

Tras la persecución emprendida por la fuerza policial y el encarcelamiento de 16 indios, quienes, "después de pasar algún tiempo en la cárcel correccional de la ciudad de Teófilo Otoni, fueron liberados y regresaron todos con sus mujeres e hijos", surgieron nuevos y más graves acontecimientos, cuando retornaron "los sediciosos de los matorrales y [recomenzaron] sus hostilidades con más osadía, realizando robos, estragos y destrucciones por el espacio de un mes y siete días". Fue así como, a 24 kilómetros del poblado, en el lugar conocido como "Capela Nova" [hoy conocida como la ciudad de Campanario], los indígenas se tomaron las "mejores casas estratégicas de los nacionales para sus futuras operaciones de atracos y conquistas".

Sin embargo, según lo estipulado por el vicedirector del establecimiento, fray Ángelo, la versión de la revuelta hace eco con la memoria regional. Para él, la revuelta fue solo aplacada "cuando los misioneros se vieron en la dura necesidad de organizar una expedición de hombres bien armados y bien proveídos de todo lo necesario para combatir a los indios, emboscados en guerrillas" (Fray Ángelo, 1915: 49). Tal vez este misionero, al elaborar la Sinopsis de la misión, asume la organización de la expedición realizada en la fiesta de San Pedro, en la Igreja Nova, cuando "más de 20 indios", entre ellos los considerados insurrectos, fueron muertos en una acción entonces atribuida únicamente a la espontaneidad de los habitantes. Los detalles revelados por el vicedirector -quien asume la autoría de la operación que puso término a los "desórdenes"- son muy disonantes en comparación a la versión oficializada por los misioneros tras la revuelta.

La expedición organizada en el Establecimiento fue encomendada a un "lenguaraz" ("língua") "fiel”, quien estaba casado con una indígena "valiente", y era un "eximio tirador y manejador del arco y de la flecha y perfecto conocedor de todos los sitios frecuentados por los salvajes". Por ejemplo, en una de las expediciones de "guerra" realizada por los soldados en la época de las divisiones militares del río Dulce, expedición también organizada por los misioneros, el "lenguaraz" y su escolta investigaron la selva durante días, pudiendo sorprender al "quijeme" perseguido al amanecer, cuando, al encontrar a los indios desprevenidos, fueron capaces de diezmarlos, colocando fin a su revuelta.

Los misioneros, de este modo, sucumbieron a la constatada superioridad de los Botocudos reunidos en "guerrillas", lo que los llevó a adoptar, durante todo el período consecutivo en que perduró la misión, una postura tan "áspera" e "intransigente" como la que habían aprendido con sus principales instructores y primeros aliados, los antiguos jefes indígenas.

La idea de la conversión indígena en la misión solo adquirió sentido tras la derrota

2 Relatório do diretor geral dos índios do Estado de Minas Gerais, Antônio Alves Pereira, ao secretário da Agricultura, Comércio e Obras Públicas, David Campista. SG 25, p. 83. APM. 
de la resistencia nativa, pues retornando los indios poco a poco, derrotados e "impelidos por el hambre" después de la revuelta, era a ellos concedido el perdón, cuyo significado remite necesariamente al "arrepentimiento", o al reconocimiento individual de la culpa de haber deseado permanecer en el pecado de la "salvajería", marca indeleble de sus existencias "perniciosas" y contrarias a la "orden" y al "progreso" nacional. Corregir tal "vicio de origen", tan arraigado y renuente, solo sería posible renegando la propia "raza", la propia familia, lo que debería ser combatido, siempre que fuese necesario, en aquella "cruzada santa" que representó la destrucción de los Botocudos, en nombre de la salvación de las almas de sus descendientes, que hoy reniegan su origen "salvaje".

\section{Conclusión}

A pesar de que el examen de las fuentes decimonónicas no ofrece la posibilidad de reconstruir la organización intrínseca al universo sociocosmológico de los botocudos, fuentes elaboradas por administradores legos o religiosos caracterizados por el pensamiento reaccionario típico del período de la restauración europea, que definían a los indígenas como insaciables fieras antropófagas (MOTTA, 2002), los indicios de la existencia de una relación directa entre la organización del movimiento histórico de los pueblos indígenas y la lógica del chamanismo guerrero, sugirieren interpretaciones etnográficas que revelan estrategias de negociación de los intereses indígenas en asociación con los intereses de los potentados locales, desarrolladas en la intermediaria y porosa región de las fronteras étnicas, donde se imbrican las lógicas nativas y la historia.

Las alteridades indígenas, en cuanto tales, no tuvieron, de hecho, un espacio de expresión en la experiencia de las misiones capuchinas en la región de Minas. Sin embargo, los esfuerzos para convertir la dominación en orden generó, entre los pueblos indígenas, resistencias y luchas para recuperar la autonomía. Aun siendo presionadas para integrarse en el orden nacional, las alteridades indígenas consiguieron imprimir el sello de su especificidad en las experiencias misioneras aquí examinadas, obligando a las autoridades a adaptar- se a las condiciones por ellas impuestas en el ejercicio tan lucrativo de su "pacificación".

Traducido por

Raúl Ortiz Contreras

\section{Agradecimiento}

Agradezco a Raúl Ortiz Contreras por el incentivo a participar del VI Congreso Chileno de Antropología, por el cálido recibimiento en la bella ciudad de Valdivia y, además, por la traducción del texto para el español.

\section{FUENTES Y BIBLIOGRAFÍA}

\section{Documentos manuscritos}

\section{Arquivo dos Capuchinhos do Rio de Janeiro}

Frei Ângelo de Sassoferrato "Synopse da Missão cathechética dos selvicolas do Mucury, norte do Estado de Minas Geraes. Esta Missão foi fundada em 1873, pelos Rev.mos Capuchinhos Seraphim de Gorizia e Ângelo de Sassoferrato no centro das matas, distantes 36 kilômetros ao sul da cidade de Theophilo Ottoni (antiga Philadelphia)". 191569 fls. Gav. C, Pasta IV.

\section{Arquivo Público Mineiro, Belo Horizonte}

TIMMERS, Olavo, 1969. "O Mucuri e o Nordeste Mineiro no passado e seu desenvolvimento segundo documentos e notícias recolhidas por Frei Olavo Timmers OFM em lembrança do $100^{\circ}$ aniversário de Teófilo Benedito Ottoni. 1869-17 de Outubro de 1969". Teófilo Otoni. Datilografado com emendas manuscritas. 535 fls.

Códices da Secretaria de Governo (18631894):

SG 22: expediente da Diretoria dos Índios (1886-1887).

\section{BIBLIOGRAFÍA}

DUARTE, R. H, org. (2002), Notícia sobre os Selvagens do Mucuri, Ed. Universidade Federal de Minas Gerais, Belo Horizonte.

Elias, N. (1995), O Processo Civilizador, Volume 2: Formação do Estado e civilização, Ed. Zahar, Rio de Janeiro. 
GOMES J. C. (1862), Relatório da Comissão Liquidadora da Companhia do Mucuri, Tipografia Nacional, Rio de Janeiro.

KÖNIG, H. J. (1998), “¿Bárbaro o símbolo de la libertad? ¿Menor de edad o ciudadano? Imagen del indio y política indigenista en Hispanoamérica", en KÖNIG, Hans-Joachim, org, . (1998), El Indio Como Sujeto y Objeto de la Historia Latinoamericana: pasado y presente. Universidad Católica de Eichstätt, Frankfurt/ Main/Madrid.

MISSAGIA DE MATTOS I. (2004), Civilização e Revolta: os Botocudos e a catequese na Província de de Minas, Anpocs/Edusc, Bauru.

MISSAGIA DE MATTOS, I. (2002), "Civilização" e "Revolta": Povos Botocudo e Indigenismo Missionário na Província de Minas, Tese de Doutorado en Ciências Sociais, Unicamp, Campinas.

MONTEIRO, J. (2001), “Entre o Gabinete e o Sertão: projetos civilizatórios, inclusão e exclusão dos Índios no Brasil Imperial”, en MONTEIRO, John. (2001), Tupis, Tapuias e Historiadores, Tese de Livre-Docência, IFCH-Unicamp.

MONTEIRO, J. (2001), Tupis, Tapuias e Historiadores, Tese de Livre-Docência, IFCH-Unicamp.
MOTTA, R. P. (2001), “Paradoxos do Pensamento Contra-Revolucionário: Joseph de Maistre". Locus: revista de história 7 (2), pp. 131-150.

OTONI, T. B. (2002 [1859]), Notícia sobre os Selvagens do Mucuri em uma carta dirigida pelo Sr. Teófilo Benedito Otoni ao Sr. Dr. Joaquim Manuel de Macedo, en DUARTE Regina Horta, org (2002). Notícia sobre os Selvagens do Mucuri, Ed. UFMG, Belo Horizonte.

PACÓ, Domingos Ramos (1996 [1918]), Hámbric anhamprán ti mattâ nhiñchopón? 1918. en RIBEIRO, Eduardo, org.(1996) Lembranças da Terra: histórias do Mucuri e Jequitinhonha, Cedefes, Contagem, pp. 198-211.

RIBEIRO, E, org. (1996), Lembranças da Terra: histórias do Mucuri e Jequitinhonha, Cedefes, Contagem.

SEYFERTH, G. (1995), A Invenção da Raça e o Poder Discricionário dos Estereótipos. Anuário Antropológico 93, pp. 175-203.

SEYFERTH, G. (1995a), La inmigracion alemana y la politica brasileña de colonizacion. Estudios Migratorios Latinoamericanos, 10 (29), pp. 53-75. 